\title{
Spontaneous Network Activity Transiently Depresses Synaptic Transmission in the Embryonic Chick Spinal Cord
}

\author{
Brent Fedirchuk, ${ }^{1}$ Peter Wenner, ${ }^{2}$ Patrick J. Whelan, ${ }^{2}$ Stephen Ho, ${ }^{3}$ Joel Tabak, ${ }^{2}$ and Michael J. O'Donovan ${ }^{2}$ \\ ${ }^{1}$ Department of Physiology, University of Manitoba, Winnipeg, Manitoba R3E 3J7, Canada, 2 Laboratory of Neural Control, \\ National Institute of Neurological Diseases and Stroke, National Institutes of Health, Bethesda, Maryland 20892-4455, \\ and ${ }^{3}$ Department of Developmental Neurobiology, Research School of Biological Sciences, Australian National University, \\ Canberra 2601, Australia
}

We examined the effects of spontaneous or evoked episodes of rhythmic activity on synaptic transmission in several spinal pathways of embryonic day 9-12 chick embryos. We compared the amplitude of synaptic potentials evoked by stimulation of the ventrolateral funiculus (VLF), the dorsal or ventral roots, before and after episodes of activity. With the exception of the short-latency responses evoked by dorsal root stimulation, the potentials were briefly potentiated and then reduced for several minutes after an episode of rhythmic activity. Their amplitude progressively recovered in the interval between successive episodes. The lack of post-episode depression in the shortlatency component of the dorsal root evoked responses is probably attributable to the absence of firing in cut muscle afferents during an episode of activity.

The post-episode depression of VLF-evoked potentials was mimicked by prolonged stimulation of the VLF, subthreshold for an episode of activity. By contrast, antidromically induced mo- toneuron firing and the accompanying calcium entry did not depress VLF-evoked potentials recorded from the stimulated ventral root. In addition, post-episode depression of VLFevoked synaptic currents was observed in voltage-clamped spinal neurons. Collectively, these findings suggest that somatic postsynaptic activity and calcium entry are not required for the depression. We propose instead that the mechanism may involve a form of long-lasting activity-induced synaptic depression, possibly a combination of transmitter depletion and ligand-induced changes in the postsynaptic current accompanying transmitter release. This activity-dependent depression appears to be an important mechanism underlying the occurrence of spontaneous activity in developing spinal networks.

Key words: synaptic depression; spontaneous activity; spinal networks; synaptic currents; chick embryo; rhythmic activity
Spontaneous activity is a characteristic feature of developing synaptic networks and has been detected in many parts of the immature nervous system (Landmesser and O'Donovan, 1984; Lippe, 1995; Itaya et al., 1995; Wong et al., 1995; Nishimaru et al., 1996; Garaschuk et al., 1998). This network-driven activity is believed to be important in the formation of neuronal networks (Katz and Shatz, 1996), but surprisingly little is known about its genesis and regulation. We have been studying this problem using the isolated spinal cord of chick embryo, which generates spontaneous episodes of rhythmic activity. During these episodes, which recur with an interval of several minutes, spinal interneurons and motoneurons are activated synchronously (O'Donovan 1989; Sernagor and O'Donovan 1991; O'Donovan et al., 1994, Sernagor et al., 1995; A. Ritter, P. Wenner, S. Ho, P. Whelan, and M. J. O'Donovan, unpublished data). The slow periodicity of the spontaneous network activity suggests some type of refractoriness, but the underlying mechanism has not yet been described.

Recently, we and others (Streit, 1993; Senn et al., 1996; O’Donovan and Chub, 1997; O’Donovan et al., 1998a; Tabak et al., 1999) have proposed that spontaneous, episodic activity can

Received Aug. 26, 1998; revised Dec. 28, 1998; accepted Jan. 5, 1999.

B.F. was the recipient of a Medical Research Council of Canada fellowship. P.J.W. was a recipient of a Natural Sciences and Engineering Research Council of Canada fellowship and an Alberta Heritage Foundation for Medical Research Fellowship.

Correspondence should be addressed to M. J. O’Donovan, Laboratory of Neural Control, National Institute of Neurological Diseases and Stroke, National Institutes of Health, Building 49, Room 3A50, 49 Convent Drive, Bethesda, MD 20892-4455. Copyright (C) 1999 Society for Neuroscience $0270-6474 / 99 / 192102-11 \$ 05.00 / 0$ emerge in recurrently connected, excitatory networks that experience some form of activity-induced depression of network excitability. The type of network depression proposed in these models recovers within seconds or minutes and differs from the long-lasting, activity-dependent synaptic modification that has been observed in other parts of the developing nervous system (Kirkwood et al., 1995; McLean et al., 1996). The purpose of the present work was to test these ideas by examining the effects of spontaneous and evoked activity on transmission through three different lumbosacral spinal pathways: first, from the ventrolateral funiculus (VLF) onto both motoneurons and interneurons (Ritter, Wenner, Ho, Whelan, and O’Donovan, unpublished data); second, from one ventral root to an adjacent ventral root (Whelan and O'Donovan, 1997; Wenner et al., 1998); and finally, from the dorsal roots onto motoneurons (Lee et al., 1988; Mendelson and Frank, 1991).

Preliminary reports of this work have been published in abstract form (Fedirchuk and O'Donovan 1996, Whelan and O'Donovan 1997) and discussed in recent reviews (O'Donovan and Chub, 1997; O'Donovan et al., 1998a,b).

\section{MATERIALS AND METHODS}

Experiments were performed on the isolated spinal cord of White Leghorn chicken embryos (embryonic days 9-12). The embryo was removed from the shell, rapidly decapitated, and placed in cooled (10$14^{\circ} \mathrm{C}$ ), oxygenated Tyrode's solution (in mM: $139 \mathrm{NaCl}, 12$ glucose, 17 $\mathrm{NaHCO}_{3}, 3 \mathrm{KCl}, 1 \mathrm{MgCl}_{2}$, and $\left.3 \mathrm{CaCl}_{2}\right)$. The lower thoracic and lumbosacral spinal cord together with attached spinal or peripheral 
nerves were dissected under a microscope. Using a fine tungsten needle, parts of the VLF were peeled off the spinal cord, rostral to the lumbosacral enlargement (T5-LS1; rVLF) and caudally within the lumbosacral enlargement (LS4-LS6; cVLF). The preparation was then slowly warmed to room temperature $\left(18-24^{\circ} \mathrm{C}\right)$ and transferred to a recording chamber where it was secured with insect pins or nylon webbing. The cord was superfused with oxygenated Tyrode's solution and slowly warmed to $27-28^{\circ} \mathrm{C}$. Suction electrodes were placed on the dorsal roots (DRs), ventral roots (VRs), rVLF, and cVLF. Neural activity was recorded with high-gain DC amplifiers (3 KHz, Grass P16; World Precision Instruments DAM70, or custom made at National Institutes of Health). Activity was either spontaneous or elicited by electrical stimulation $(2-65 \mu \mathrm{A}, 50-500 \mu \mathrm{sec})$ of the cord. Neural recordings were digitized (Neuro-corder DR-886, Neuro Data Instruments) and recorded on videotape for later analysis using custom computer software. In some experiments, the evoked potentials were filtered at $0.01-500 \mathrm{~Hz}$ and digitized $(1 \mathrm{kHz})$ using a analog-to-digital board (General Instruments). Data are presented as means \pm SEM.

Whole-cell recordings. Recordings were made from single motoneurons and presumptive interneurons using the blind patch technique (Blanton et al., 1989) adapted for the chick spinal cord (Sernagor and O'Donovan, 1991). Electrodes were pulled on a Brown-Flaming electrode puller and had resistances ranging from 3 to $8 \mathrm{M} \Omega$. The patch solution contained (in $\mathrm{mm}$ ): $130 \mathrm{KMeSO}_{3}, 10 \mathrm{NaCl}, 1.1 \mathrm{EGTA}, 10 \mathrm{HEPES}, 1 \mathrm{Na}_{2} \mathrm{ATP}, 1$ $\mathrm{MgCl}_{2}$, and $1 \mathrm{CaCl}_{2}$. Recordings were obtained by slowly advancing the electrode through the ventral surface of the lumbosacral cord. Slight positive pressure was applied to the electrode during its advance. When the electrode was in the gray matter and a slight resistance change was observed, the positive pressure was removed, and light suction was applied. If a stable gigaohm seal was formed, a pulse of suction was used to rupture the membrane. Intracellular recordings were made using an Axoclamp 2A amplifier (series resistance uncompensated) in current- or voltage-clamp mode.

Neurons were distinguishable from glia by their ability to produce action potentials in response to intracellular current injection. Neurons $(n=29)$ were included in the study if their resting membrane potential was more negative than $-40 \mathrm{mV}$. Four of these cells were identified as motoneurons by antidromic stimulation from the sartorius muscle nerve $(n=3)$ or the ventral root $(n=1)$, and two were identified as VLF interneurons by antidromic stimulation of the VLF. The reminder $(n=$ 23) were not antidromically activated from either source.

Imaging. Ventral roots were loaded with a $25-50 \%$ solution of calcium green dextran in $0.2 \%$ Triton X-100 (O’Donovan et al., 1993). The cord was left overnight at $17^{\circ} \mathrm{C}$ to allow labeling of the motoneuron cell bodies. The next morning, it was placed in a chamber on the stage of an inverted microscope (Nikon), and the lateral motor column was imaged with an intensified CCD camera (Stanford Photonics). Video data were taped and analyzed later using a commercial image analysis program (Metamorph, Universal Imaging).

\section{RESULTS}

Our strategy was to investigate the effects of spontaneous activity on several distinct pathways we knew to be active during an episode. The first was the pathway from the VLF onto both motoneurons and interneurons. This was selected because previous work had shown that some of the interneurons projecting into the VLF were active during spontaneous episodes (O'Donovan et al., 1994, O'Donovan and Ritter, 1995; Ritter, Wenner, Ho, Whelan, and O'Donovan, unpublished data). The second pathway was the disynaptic, recurrent connection between motoneurons, which may be equivalent to the mammalian Renshaw pathway (Whelan and O’Donovan, 1997; Wenner et al., 1998). Again, our previous work had shown that the interneurons in this disynaptic pathway were active during spontaneous episodes (O'Donovan et al., 1998b; Wenner et al., 1998).

We were also interested in comparing the effects of spontaneous activity on synaptic transmission in a pathway that was not active during spontaneous episodes. For this reason we examined the projection from the cut dorsal roots onto motoneurons (Lee et al., 1988; Mendelson and Frank, 1991). Stimulation of the dorsal roots evokes a short-latency response in motoneurons that is mediated monosynaptically and disynaptically and a longlatency, polysynaptic response (Lee et al., 1988; Lee and O'Donovan, 1991). We assumed that cut primary afferent fibers, projecting monosynaptically to motoneurons, would not fire during an episode. By contrast, the interneurons mediating polysynaptic excitation should be active, because the majority of ventral interneurons are rhythmically driven during an episode (Ritter, Wenner, Ho, Whelan, and O'Donovan, unpublished data). This allowed us to compare the effects of spontaneous episodes on the active and inactive components of a pathway projecting to a common set of motoneurons.

\section{Modulation of VLF-evoked potentials by spontaneous episodes of activity}

Electrical stimulation of either the rostral or the caudal VLF evoked synaptic potentials in the ventral roots and in the unstimulated part of the VLF (Fig. 1). These potentials were prolonged and sometimes had distinct short- and long-latency components (Fig. $1 B, b$ ). Previous work has shown that the early component of the VLF-evoked response (Fig. $1 B, b$, arrow) is probably generated by monosynaptic and disynaptic projections, whereas the long-latency responses reflect recruitment within a recurrently connected population of interneurons (Ritter, Wenner, Ho, Whelan, and O'Donovan, unpublished data; also see Is postsynaptic activity required for the depression? and Discussion).

After either a spontaneous or an evoked episode, the VLFevoked potentials were initially potentiated and then depressed (Fig. $1 B$ ). Potentiation was observed throughout the episode and as the episode depolarization was decaying (Fig. 1A, asterisk). This potentiation presumably occurred because transmission through polysynaptic pathways was facilitated while the neurons were depolarized (because the intercalated interneurons would be close to, or suprathreshold for, action potentials). Consistent with this interpretation, we found that the potentiation was particularly marked for the long-latency, polysynaptic components of the evoked response (Fig. $1 B, b$ and $b-a$ ). The subsequent depression of the VLF-evoked potential was persistent, lasting for several minutes. The amplitude of the potentials slowly recovered in the interval between successive, spontaneous episodes.

We quantified the time course of the depression by stimulating the VLF once every $10 \mathrm{sec}$ in the interval between episodes and measuring the amplitude of the potentials evoked in the ventral roots and the VLF. Figure 2 illustrates the time course of recovery for an individual experiment and pooled data from several experiments. The individual (Fig. 2A) and pooled (Fig. 2B) ventral root data are shown on a non-normalized time scale to illustrate the time course of the recovery. The evoked potentials decayed from their initial potentiation and reached a minimum amplitude $\sim 1-2$ min after the end of the episode. At this time the potentials evoked in the ventral roots had declined to $39 \pm 3 \%$ of their control value just before the episode $(n=3$ experiments; Fig. 2B). VLF-evoked potentials recorded from the VLF behaved similarly and exhibited their maximal depression $(52 \pm 4 \%$ of control) 1-2 min after the end of the episode $(n=5$ experiments; Fig. 2C). After this minimum, the amplitude of the potentials recovered progressively until the next episode. We found considerable interexperiment variability in the extent of the depression. For example for the five experiments used to construct the graph of Figure $2 C(V L F \rightarrow V L F)$, the maximal depression ranged from $40-82 \%$ of the pre-episode control amplitude. We have not investigated the source of this variability. Among the factors that could be involved are the number and type of axons 


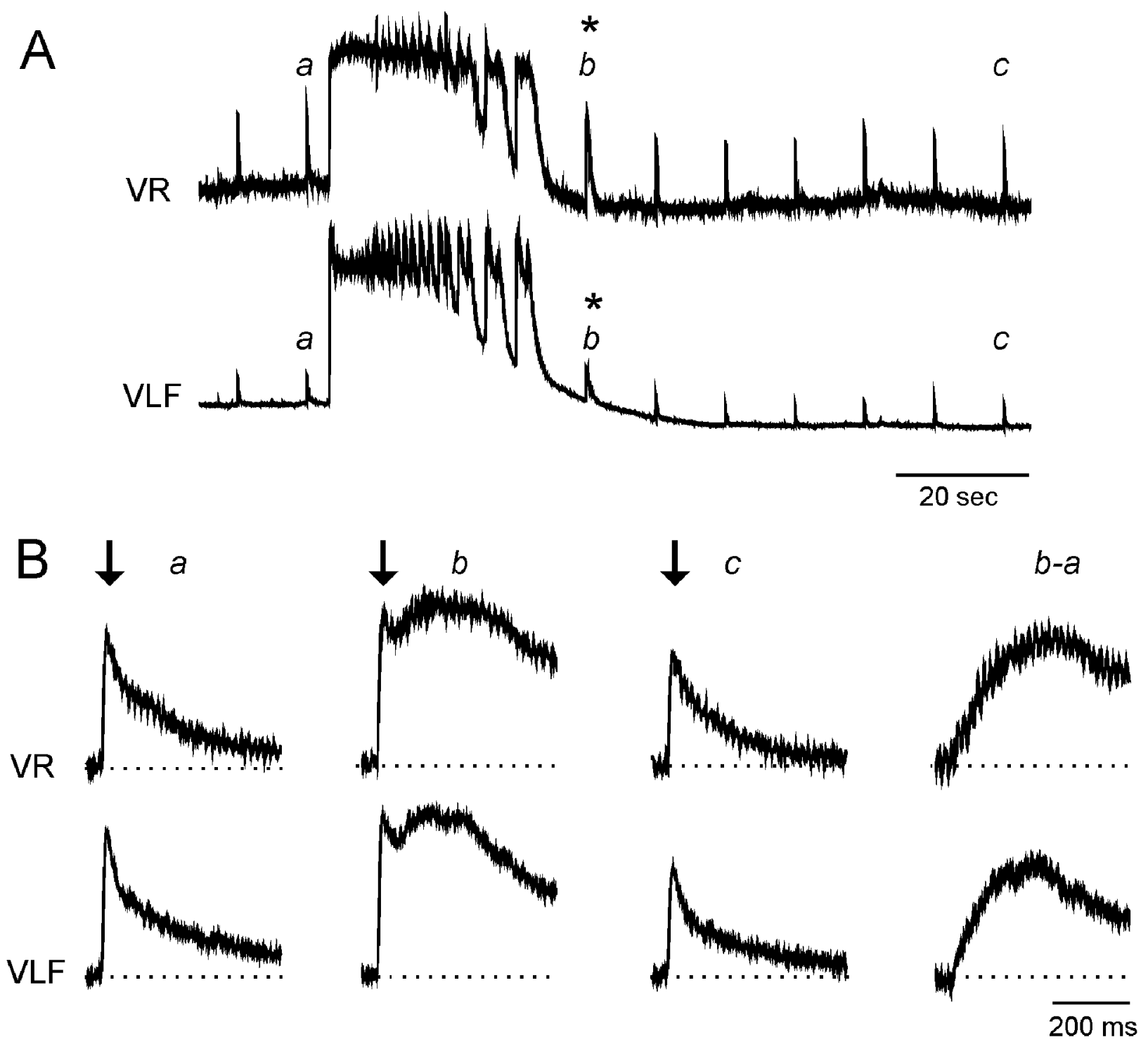

Figure 1. VLF-evoked potentials recorded in both the ventral roots and VLF are initially potentiated (asterisks) and then reduced after a spontaneous episode of rhythmic activity. $A, \mathrm{VR}$ and VLF recordings on a slow time scale. The rostral VLF was stimulated repetitively at $0.1 \mathrm{~Hz}$. Examples of the evoked potentials produced in the VR and VLF are shown on a faster time scale in $B$. The short-latency component of the VLF-evoked responses is indicated by the arrows in $B$. Traces $b-a$ in $B$ show the difference between the potentiated response $(b)$ and the control $(a)$.

recruited by the test stimulus and the duration and intensity of network activation during episodes. Although the depression was quantitatively variable from embryo to embryo it was, nevertheless, a robust phenomenon and was observed in every preparation.

\section{Modulation of recurrent, motoneuronal responses by spontaneous episodes of activity}

In the next set of experiments, we sought to establish whether the post-episode depression was expressed in another pathway we knew was active during spontaneous episodes. For this reason, we chose the pathway mediating recurrent connections between motoneurons (Whelan and O'Donovan, 1997; Wenner et al., 1998). Transmission in this pathway was also depressed after spontaneous activity and recovered in the interval between spontaneous episodes (Fig. 3A,B). In three experiments the recurrent ventral root potential evoked by stimulation of an adjacent root was depressed to $49 \pm 20 \%$ at $10 \%$ of the interepisode interval, and this recovered to $93 \pm 2 \%$ by $90 \%$ of the interepisode interval (Fig. 3C). We did not examine responses during an episode, because the pathway was stimulated too infrequently $(1 / 30-1 / 60 \mathrm{~Hz})$.

\section{Modulation of dorsal root afferent pathways by spontaneous episodes of activity}

Dorsal root evoked potentials were initially potentiated (Fig. 4A, asterisk) and then depressed by a spontaneous episode. However, only the late component of the dorsal root-evoked responses was affected. The short-latency response recorded from the ventral roots or the VLF was largely unchanged after the episode (Fig. $4 B, C$, arrows). After an episode the short-latency component of the dorsal root evoked response was $111 \pm 17 \%$ of the preepisode control amplitude in the ventral roots $(n=4$ experiments) and $93 \pm 10 \%$ of the pre-episode control amplitude in the VLF ( $n=3$ experiments). By contrast, the long-latency component was reduced to $12 \pm 6 \%$ of the control amplitude in the 


\section{$A \quad V L F \rightarrow V R$}
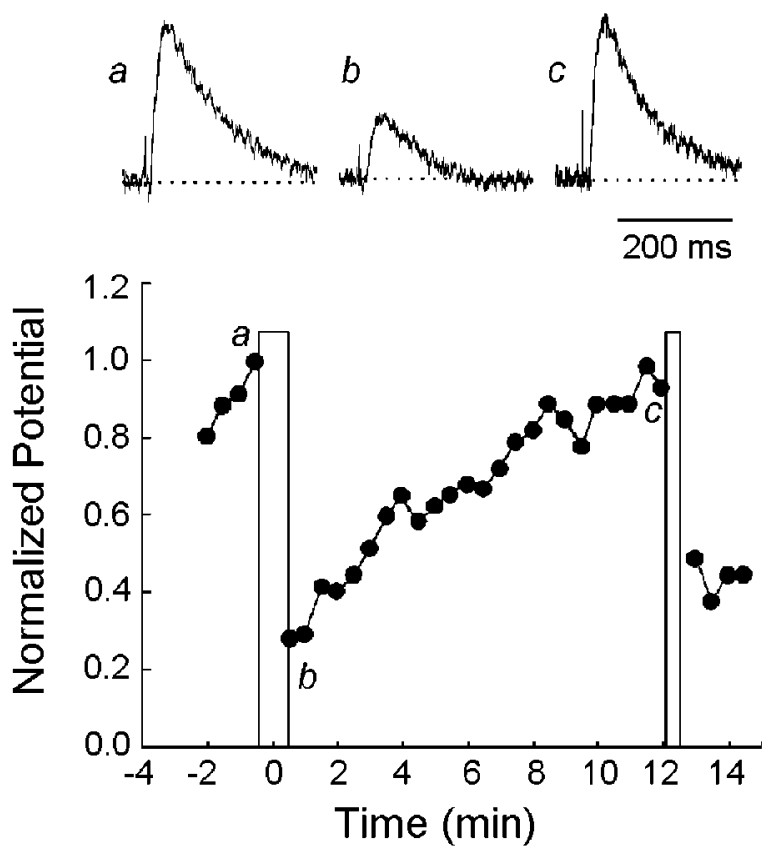

\section{B $V L F \rightarrow V R$}

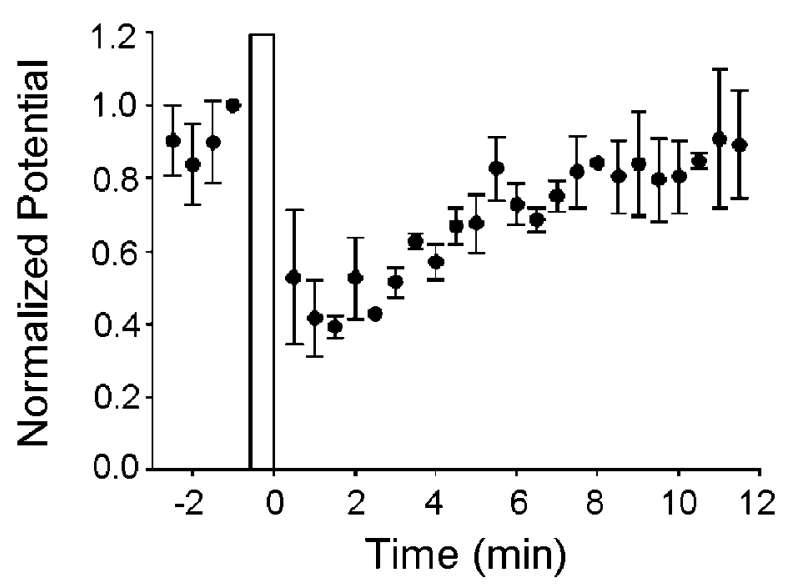

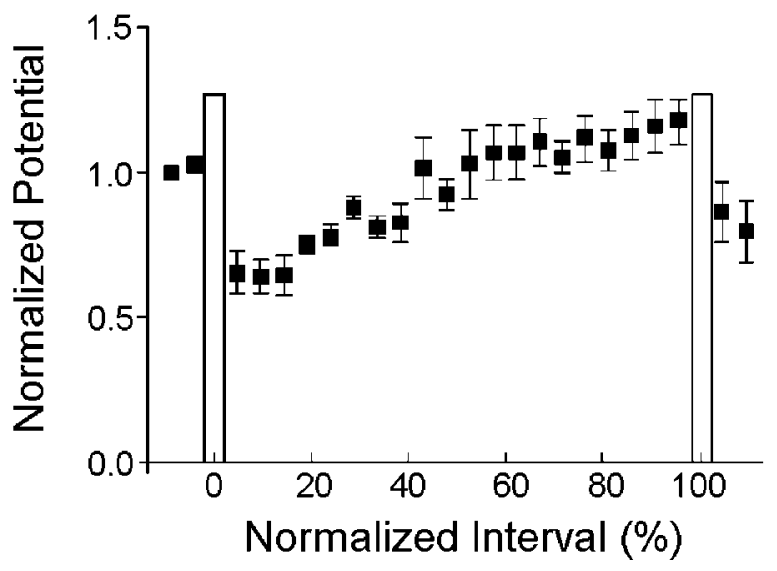

Figure 2. Time course of the depression and recovery of VLF-evoked potentials recorded from the ventral roots and from the VLF after an episode of spontaneous activity. $A$, The time course of the changes in the normalized peak amplitude of the VLF-evoked potentials recorded from a ventral root is plotted for a single experiment. Sample potentials are shown above the graph at the times indicated. The vertical bars indicate the time of spontaneous episodes. B, Average of three experiments to show the time course of the depression and recovery of VLF-evoked potentials recorded from the VRs. $C$, Average of five experiments showing the time course of the depression and its recovery for VLF-evoked potentials recorded from the VLF. Notice in $C$ the time base has been normalized for comparison with subsequent figures. In $B$ and $C$ data are plotted as the mean \pm SEM. The pooled data were measured from a single interepisode interval in each experiment.

ventral roots ( $n=4$ experiments) and to $12 \pm 7 \%$ of the control amplitude in the VLF ( $n=3$ experiments). These results are consistent with the idea that the inactive dorsal root projections onto motoneurons or interneurons, which are responsible for the short-latency responses, are not subject to post-episode depression. Although the dorsal roots are subject to primary afferent depolarization (PAD) during an episode (Ho and O'Donovan, 1993; Chub and O'Donovan 1998a), we have no evidence that PAD induces spike invasion of muscle afferent terminals. Indeed, our previous work has shown that monosynaptic muscle afferent connections with motoneurons are very susceptible to depression at low frequencies of stimulation (Lee et al., 1988; Lee and O'Donovan 1991). As a result, if the muscle afferents had been discharging during the episode, we should have observed postepisode depression.

\section{Is postsynaptic activity required for the depression?}

The first point we wanted to establish was whether the occurrence of an episode was required for the depression or whether pro- longed activity alone would be sufficient. For this reason we stimulated the VLF with a train $(4-10 \mathrm{~Hz}$ for $30 \mathrm{sec})$, subthreshold for an episode, and determined the effect on the VLF-evoked responses recorded from the ventral roots (Fig. $5 A, B$ ). This type of VLF stimulation caused a long-lasting depression, similar to that after an episode, in the amplitude of the evoked synaptic potentials. For example, in the experiment illustrated in Figure $5 A$ the amplitude of the VLF-evoked potential recorded from the ventral roots declined to $48 \%$ of its prestimulus control level after the stimulus train applied to the VLF. In the same experiment, a spontaneous episode depressed the VLF-evoked potential to $28 \%$ of the control value. In three experiments the VLF train depressed the VLF-evoked responses to $56 \pm 7 \%$ of the control value, whereas spontaneous activity depressed the VLF-evoked potentials to $39 \pm 7 \%$ of the control amplitude. These findings are consistent with the idea that neural activity is responsible for the depression, but we cannot exclude the possibility that other processes, occurring during the episode, could also contribute. 
A
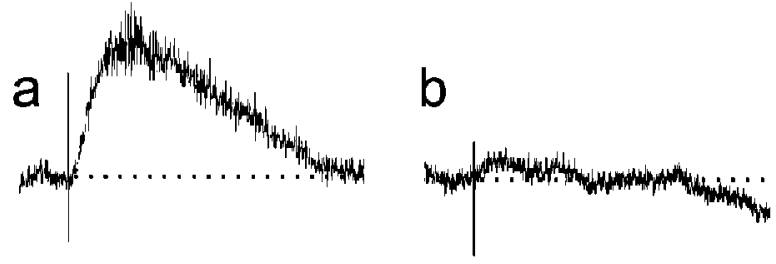

B

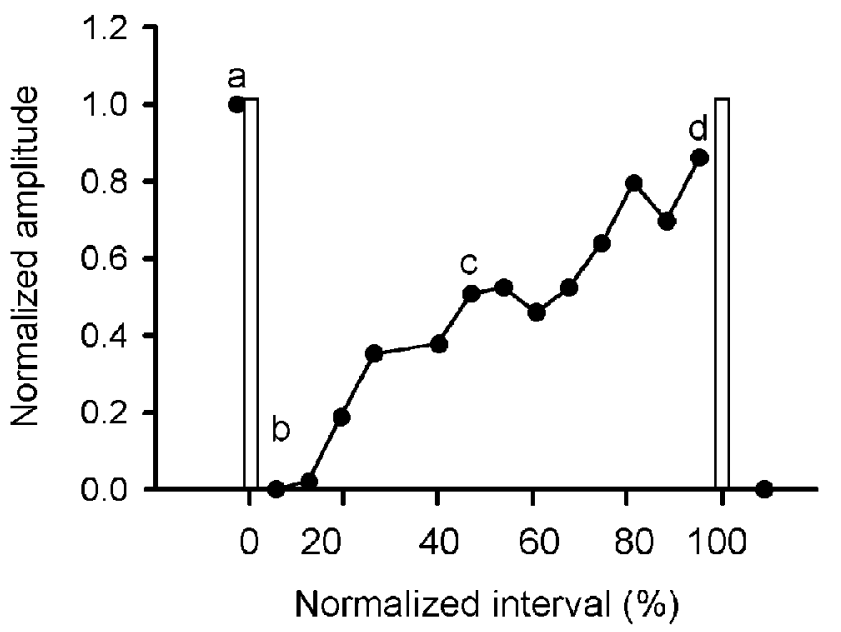

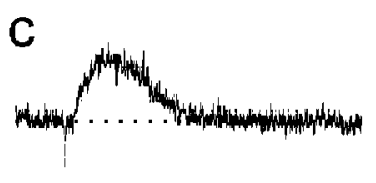

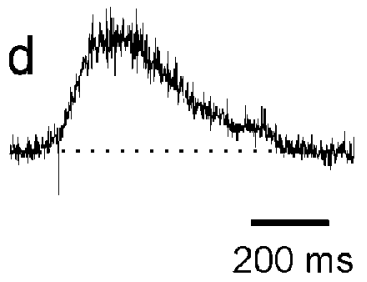

C

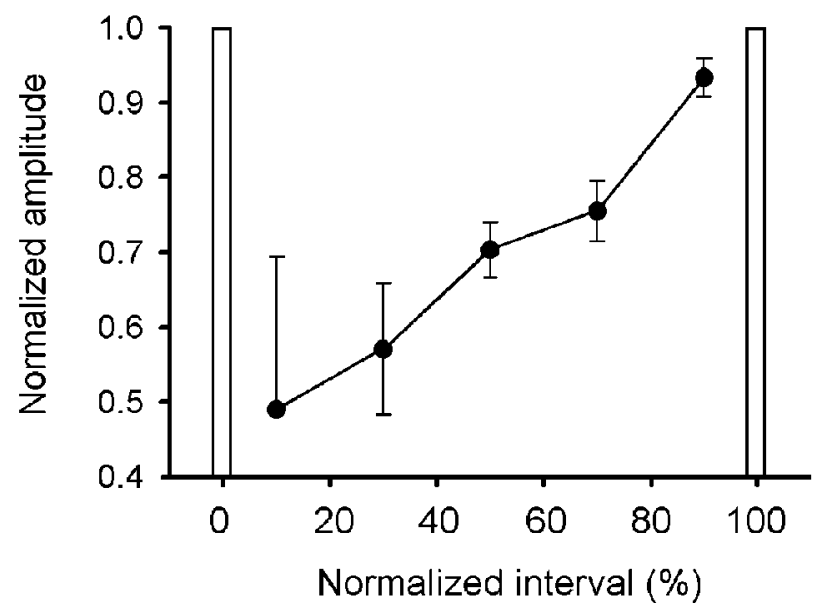

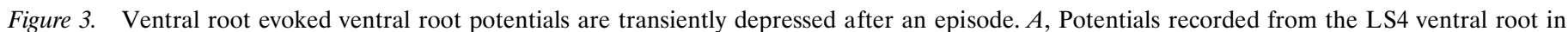

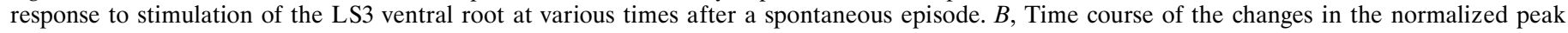

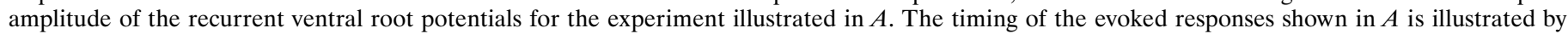

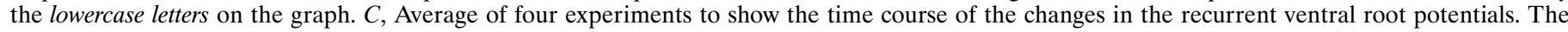

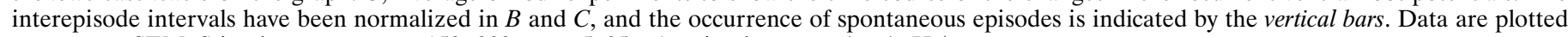
as mean \pm SEM. Stimulus parameters: 150-300 $\mu \mathrm{sec} ; 5-35 \mu \mathrm{A}$; stimulus rate, 1/30-1/60 Hz).

In the next set of experiments, we sought to establish whether the post-episode depression depended on the state of the cells in which the potentials were evoked. We knew that changes in input resistance could not account for the depression, because the input resistance of spinal neurons increases 1-2 min after an episode and then progressively falls until the next episode (Chub and O'Donovan, 1995). To investigate the role of postsynaptic firing, somal depolarization, and calcium entry, we established whether the post-episode depression occurred in voltage-clamped spinal neurons. Figure $6 A$ shows an example of such a recording and demonstrates that the depression of synaptic transmission still occurs when the somatic voltage changes, associated with the episode, are minimized by the clamp. This type of recording revealed that the depression affected the earliest components of the evoked response (within $10 \mathrm{msec}$ of the stimulus), strongly supporting the idea that the direct, monosynaptic connections are subject to the depression. Although latencies can be difficult to interpret, monosynaptic connections between muscle afferents and motoneurons have an average latency (to the onset of the potential) of $10 \mathrm{msec}$ over a conduction distance similar to that involved in the VLF-evoked responses shown in Figure 6. By contrast, the minimum polysynaptic latency of muscle afferent evoked responses in motoneurons is 16-20 $\mathrm{msec}$ (Lee and O’Donovan, 1991).

The post-episode recovery of the voltage-clamped synaptic currents is illustrated in Figure $6 B$. In this experiment, the stimulus intensity applied to the VLF was low, resulting in considerable fluctuations in the amplitude of the evoked, probably monosynaptic, synaptic current. Nevertheless, there was a clear depression in the currents after the episode, reaching a minimum 1-2 min after the episode. Similar findings were made in 10 of 14 other cells, including 2 sartorius motoneurons and 8 unidentified spinal neurons (Fig. 6C,D). In four cells (one sartorius motoneuron and three unidentified cells) no modulation of the synaptic current was seen. The absence of modulation in these cells may have been the result of cellular damage. None of the four cells exhibited the potentiation that occurs during the episode, which is consistently recorded from the ventral roots, the muscle nerves, and the majority (11 of 12) of neurons displaying post-episode depression of the evoked currents. This potentiation is believed to occur because polysynaptic pathways are facilitated when neurons are depolarized during the episode. It should, therefore, be detected in a healthy cell.

These experiments demonstrated that the post-episode depression occurred in spinal neurons in which firing, membrane potential changes, and calcium entry at the soma were prevented by voltage clamp. In the next set of experiments, we extended these observations by investigating whether the post-episode depression occurred in motoneurons induced to fire antidromically rather than synaptically. For this purpose, we antidromically 


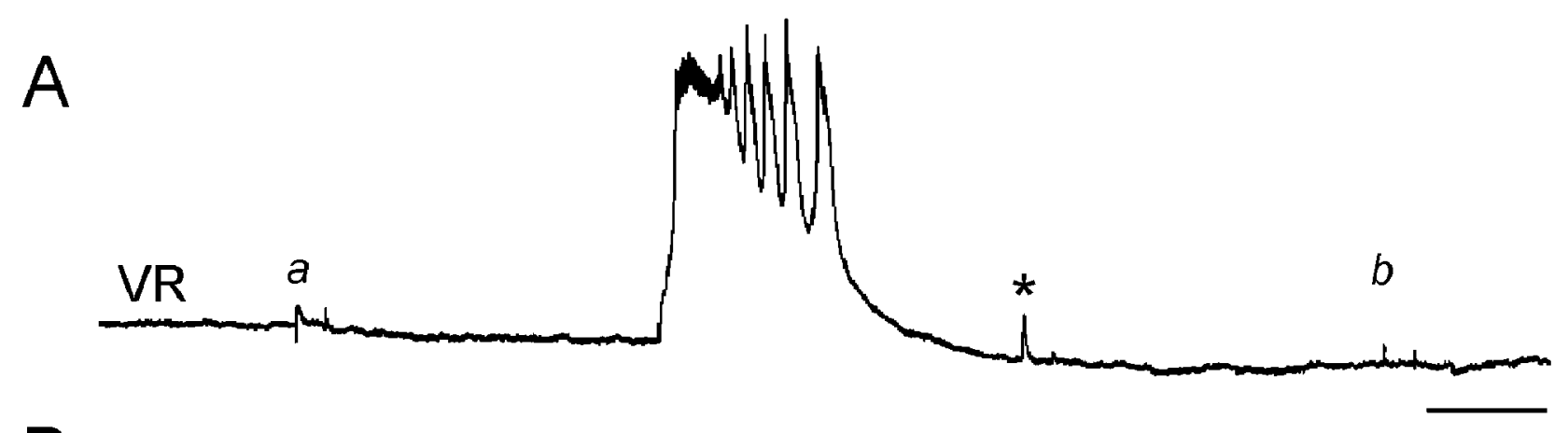

B $\quad \mathrm{DR} \rightarrow \mathrm{VR}$
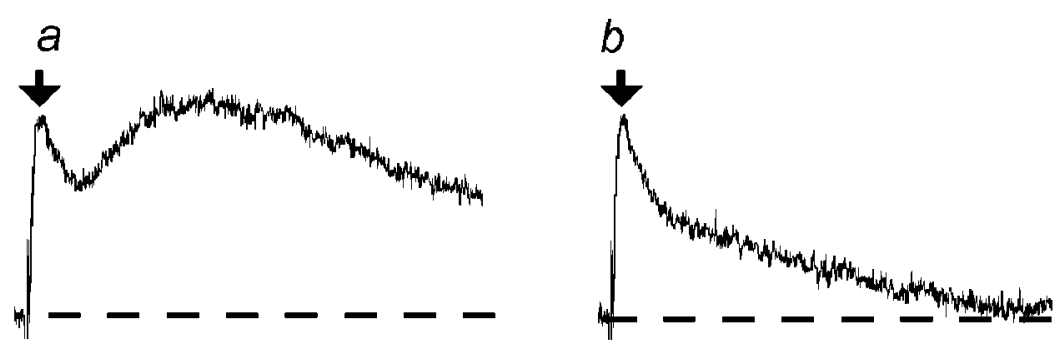

\section{DR $\rightarrow$ VLF}

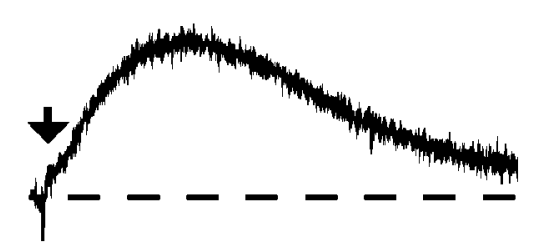

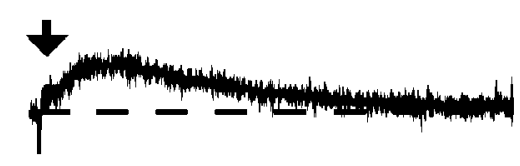

$200 \mathrm{~ms}$ $a-b$
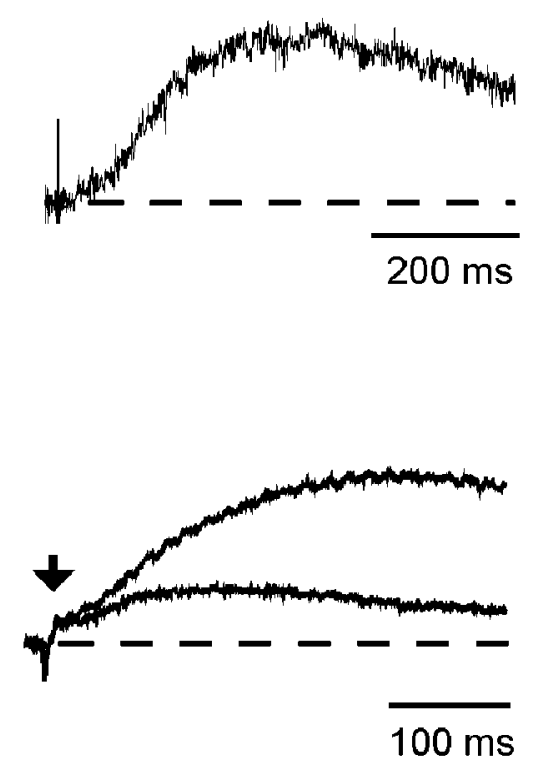

Figure 4. A, Ventral root potentials evoked by DR stimulation are transiently potentiated (asterisk) and then depressed after an episode of rhythmic activity. $B$, Dorsal root evoked responses recorded in the ventral root $(D R \rightarrow V R)$ before $(a)$ and after $(b)$ an episode of rhythmic activity. Each ventral root record was generated by averaging the responses before and after three episodes. The difference between the averages obtained before and after the episodes is shown in panel $a-b$. $C$, Dorsal root evoked potentials recorded from the VLF $(D R \rightarrow V L F)$ before and after an episode, recorded from an embryo different from that shown in $A$ and $B$. The last panel in $C$ shows the first two records superimposed and displayed on a faster time scale. The early component of the evoked responses is identified by arrows in $B$ and $C$.

stimulated motoneurons through their axons in a ventral root and monitored the effects on the VLF-evoked potentials recorded from the same ventral root. Antidromic stimulation activates motoneurons directly and also "Renshaw-like" interneurons to which the motoneuron collaterals connect. These interneurons project back to motoneurons and also connect with other spinal interneurons (Wenner et al., 1998). Because of these interneuronal projections, ventral root stimulation can sometimes trigger an episode. For this reason, we carefully monitored the effects of the ventral root train and excluded from our analysis any instances when an episode was triggered. To confirm that motoneurons were antidromically activated, in two of five experiments we retrogradely filled the motoneurons of one segment with calcium green dextran and monitored the fluorescence changes during ventral root stimulation (O'Donovan et al., 1993). These experiments also allowed us to establish whether the calcium entry accompanying antidromic firing would result in a depression of the evoked synaptic responses recorded from motoneurons.
The ventral roots were stimulated at $5-10 \mathrm{~Hz}$ to deliver $200-$ 500 pulses. VLF stimuli were delivered at $1 / 10 \mathrm{~Hz}$ before and after the antidromic train, and the evoked responses were monitored from the ventral root that was stimulated antidromically. In the experiment shown in Figure 7, motoneurons in LS1 were loaded with calcium green dextran, and the fluorescence changes were monitored during stimulation of the LS1 ventral root (Fig. 7, Antidromic) and also during the occurrence of a spontaneous episode (Fig. 7, Spontaneous). The VLF-evoked potentials recorded from LS1 (or other roots) were not depressed after the antidromic train and continued their upward trajectory as they recovered from the previous spontaneous episode. By contrast, a spontaneous episode depressed the evoked potentials (Fig. 7). Although not illustrated, the potentials fully recovered after the episode, and the preparation continued to generate robust activity.

Similar findings were made in another experiment in which the motoneurons were labeled with calcium green dextran and in 

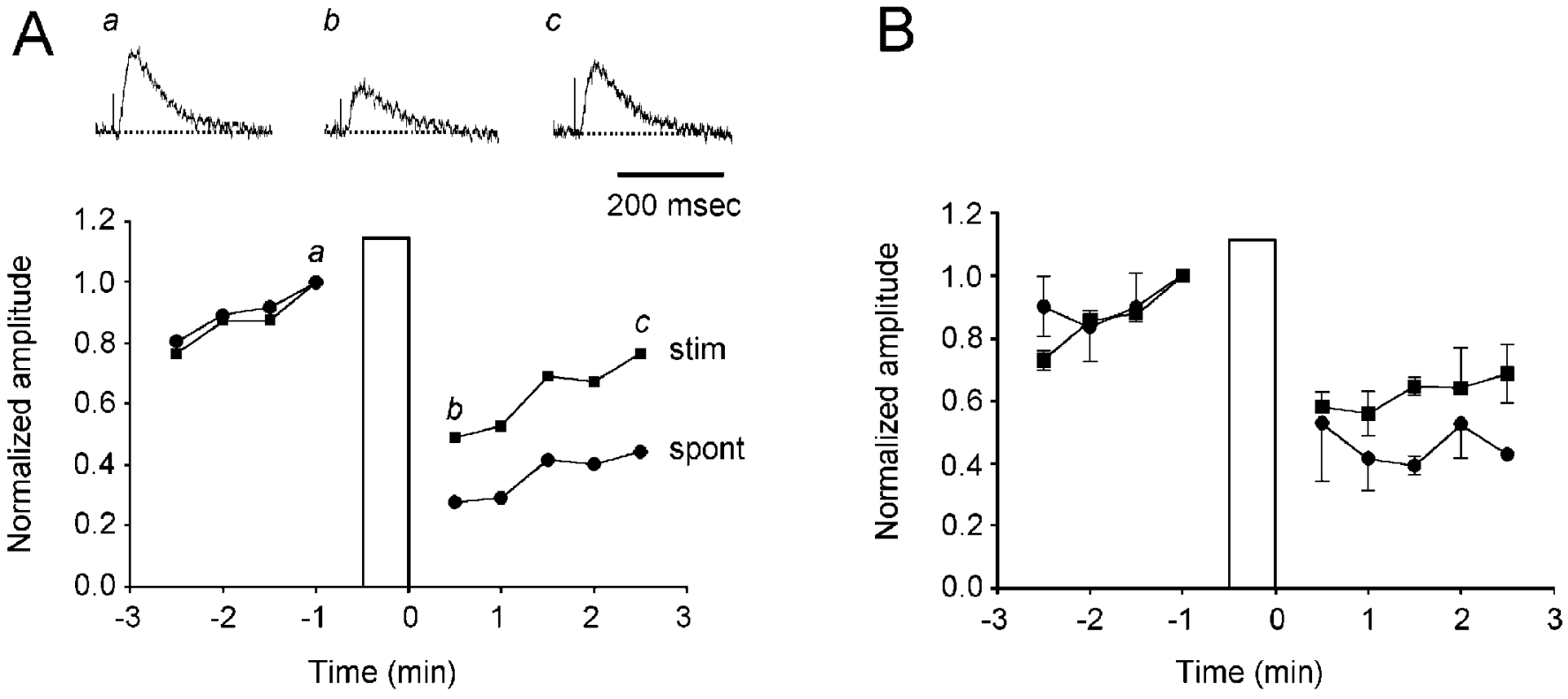

Figure 5. Comparison between the effects of prolonged stimulation of the VLF and spontaneous activity on the depression of VLF-evoked responses recorded from the ventral roots. $A$, Curves comparing the normalized amplitude of VLF-evoked potentials recorded in the ventral roots before and after a spontaneous episode (spont, filled circles) or a train of stimuli applied to the VLF (4 Hz for $30 \mathrm{sec}$; stim, filled squares). The vertical bar indicates the occurrence of an episode or the stimulus train. The VLF was stimulated once every $10 \mathrm{sec}$, and three successive responses were averaged to obtain each data point. Above the graph are sample records of the VLF-evoked responses before $(a)$ and after $(b, c)$ the VLF train obtained at the times indicated by the lowercase letters on the graph. B. Plots comparing the normalized amplitude of VLF-evoked potentials recorded in the ventral roots before and after a spontaneous episode or a stimulus train applied to the VLF pooled from three experiments. The stimulus train was 30 sec long and varied from 4 to $10 \mathrm{~Hz}$. The vertical bar indicates the time of the episode or the stimulus train. Data are shown as mean \pm SEM. The data for the spontaneous episodes are the same as those plotted the first part of the graph (up to $3 \mathrm{~min}$ ) of Figure $2 \mathrm{~B}$.

three other experiments in which calcium imaging was not used. Thirty to $60 \mathrm{sec}$ after the end of the antidromic train, the amplitude of the evoked potentials was $103 \pm 3 \%$ of the control (range, 93-112\%; $n=5$ experiments). In the same experiments VLFevoked potentials were reduced to $76 \pm 4 \%$ of the control amplitude after a spontaneous episode (range, 69-86\%, $n=4$ experiments). Although the post-episode depression recorded in these experiments was less marked than in some of the other experiments, presumably because of interexperiment variation (see Modulation of VLF-evoked potentials by spontaneous episodes of activity), this is unlikely to explain the absence of depression after the antidromic train. Not only was the depression consistently observed after each episode, it was never seen after the antidromic train. More compellingly, however, the antidromic train failed to interrupt the recovery from depression caused by a previous episode (Fig. 7). Collectively, therefore, these experiments indicate that the firing and calcium entry accompanying antidromic stimulation are insufficient to depress the synaptic potentials evoked in motoneurons.

Finally, we wanted to ensure that the VLF-evoked synaptic potentials did not exhibit an unusual voltage dependence that might explain their depression after an episode. This was important because spinal neurons are hyperpolarized by as much as 10 $\mathrm{mV}$ after an episode. This hyperpolarization recovers as a depolarizing ramp in the interval between episodes (Chub and O'Donovan, 1995). To investigate the voltage dependence of the synaptic potentials, we stimulated the VLF and recorded from neurons in either current clamp or voltage clamp. In all six neurons tested (one identified VLF interneuron and five unidentified spinal neurons), current-induced hyperpolarization increased the amplitude of the depolarizing VLF-evoked PSP. This finding indicates that the post-episode hyperpolarization of spinal neurons cannot account for the depression of synaptic transmission after an episode.

\section{DISCUSSION}

We have described a long-lasting depression of synaptic transmission in several pathways of the embryonic spinal cord after spontaneous episodes of rhythmic activity. The depression recovers with a time course similar to the interval between spontaneously occurring episodes. This prolonged synaptic depression represents a new form of activity-dependent plasticity that may underlie the expression of periodic activity by developing spinal networks.

\section{Where is the site of the post-episode depression of synaptic potentials?}

\section{Depression of short-latency responses}

The shortest latency VLF-evoked synaptic potentials are probably mediated through monosynaptic and disynaptic connections. The shortest latency responses recorded intracellularly had a latency of $<10 \mathrm{msec}$ (see Fig. 6), which means they are almost certainly mediated monosynaptically. In addition, our previous work has shown that the average latency of VLF-evoked potentials recorded in spinal interneurons was 9 msec (Ritter, Wenner, Ho, Whelan, and O'Donovan, unpublished data). By comparison, monosynaptic muscle afferent EPSPs evoked in motoneurons (over a similar conduction distance) have an average latency of 10 msec, whereas polysynaptic EPSPs have a minimum latency of 16 msec (Lee and O'Donovan, 1991).

Depression of monosynaptic potentials after a spontaneous episode could occur at three sites: first, a failure of action potential invasion into presynaptic terminals; second, at the level of the presynaptic terminal; and finally, at the postsynaptic membrane. 

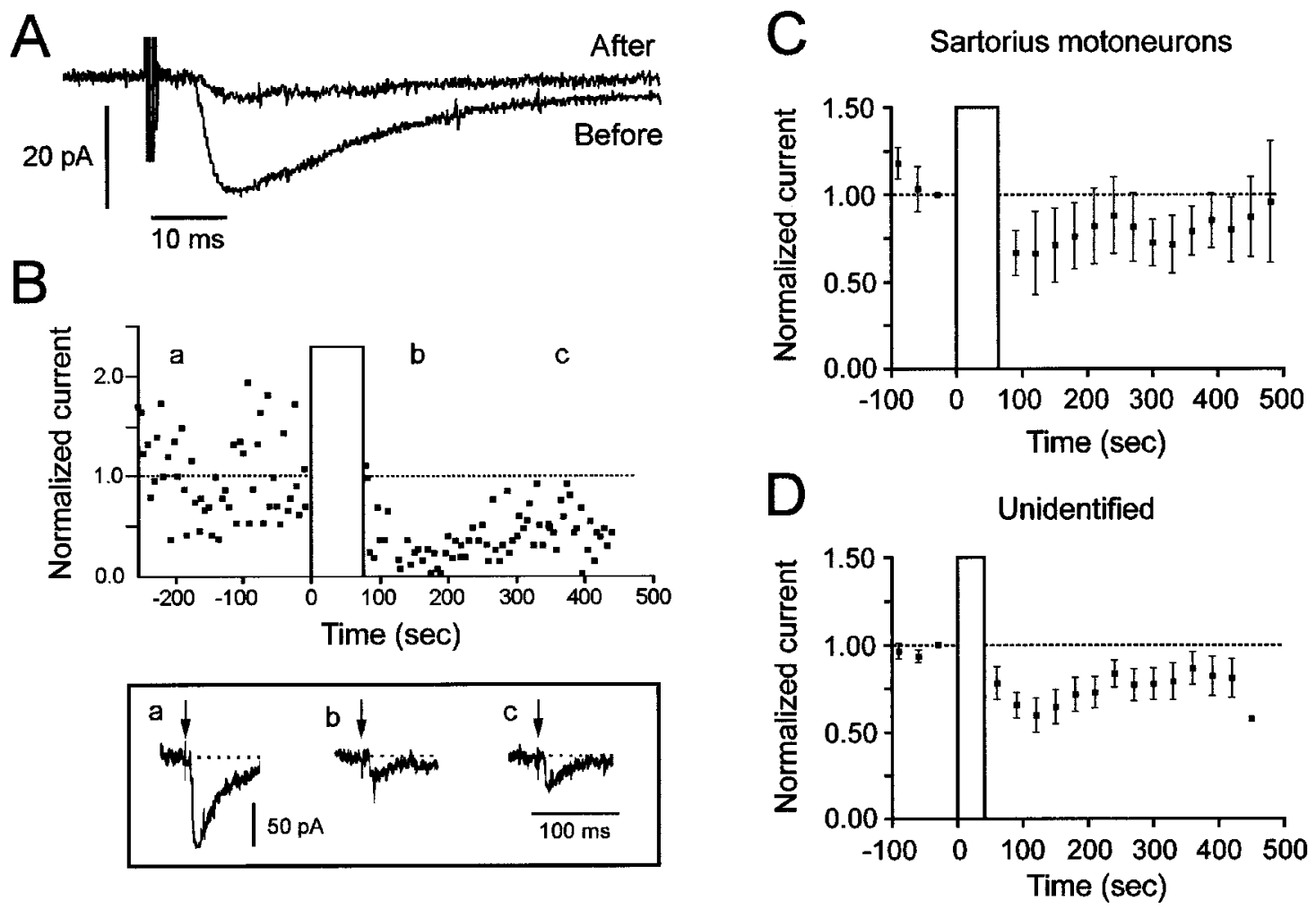

Figure 6. The post-episode depression of VLF-evoked synaptic currents occurs in voltage-clamped spinal neurons. $A$, Example of a VLF-evoked synaptic current recorded in an unidentified lumbosacral neuron before and $2 \mathrm{~min}$ after an episode of activity. The traces are averaged from 10 successive stimuli given at $1 / 5 \mathrm{~Hz}$. B, Normalized synaptic currents evoked by VLF stimulation in a ventrally located spinal neuron. The VLF was stimulated once every $5 \mathrm{sec}$. The bottom panel shows three evoked currents obtained at the times indicated by the letters over the traces. Arrows in the inset indicate the stimulus artifact. $C$, Post-episode depression and recovery of voltage-clamped synaptic currents averaged from three sartorius motoneurons, including one that was not modulated (mean $\pm \mathrm{SEM}$ ). $D$, Post-episode depression and recovery of voltage-clamped synaptic currents averaged from nine unidentified, ventrally located neurons (mean \pm SEM). Vertical bars indicate the occurrence of evoked episodes.

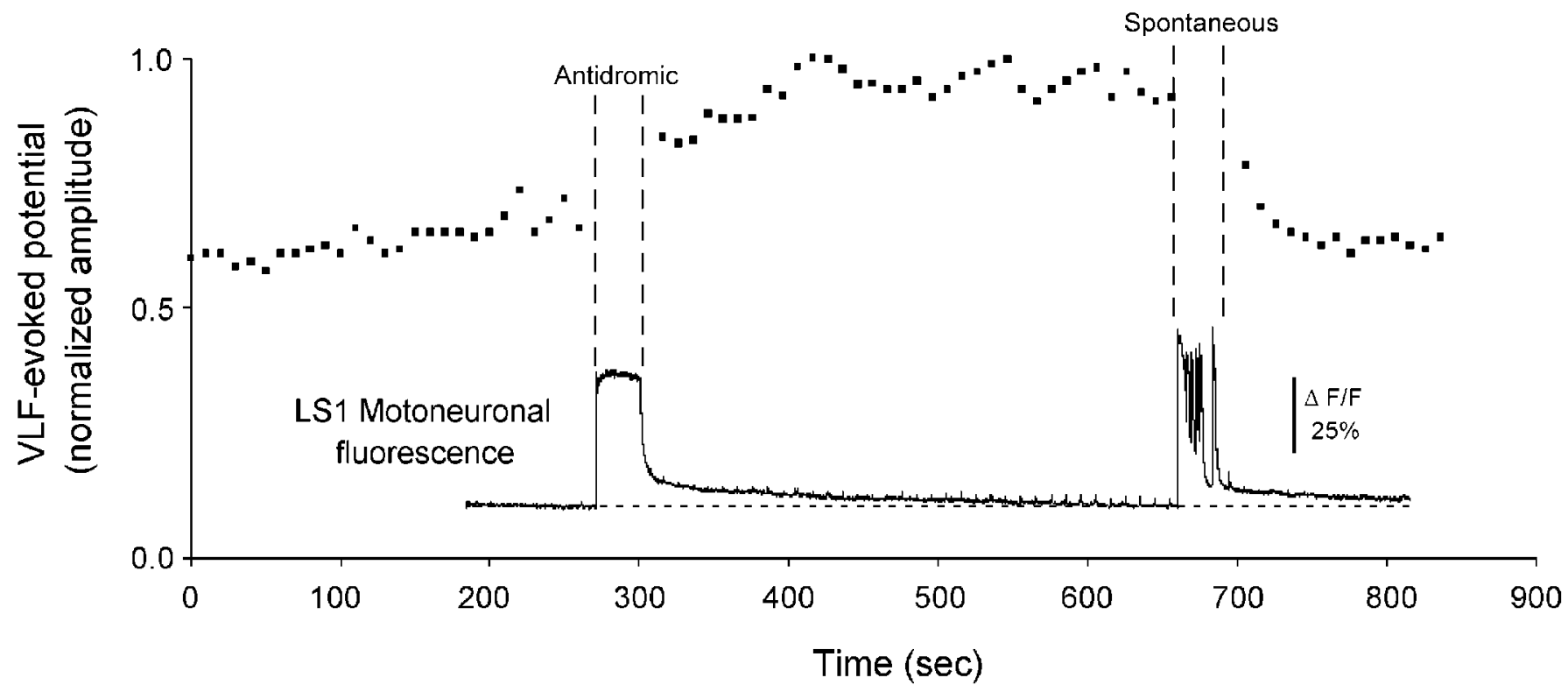

Figure 7. Antidromic activation of motoneurons does not depress VLF-evoked potentials recorded from the stimulated ventral root. The graph plots the normalized amplitude of the VLF-evoked potentials recorded from the LS1 ventral root before and after antidromic stimulation of the LS1 ventral root (Antidromic) and before and after the occurrence of a spontaneous episode (Spontaneous). Also shown on the same time scale are the fluorescence changes recorded simultaneously from LS1 motoneurons back-filled with calcium green dextran. 
A

Pre-episode

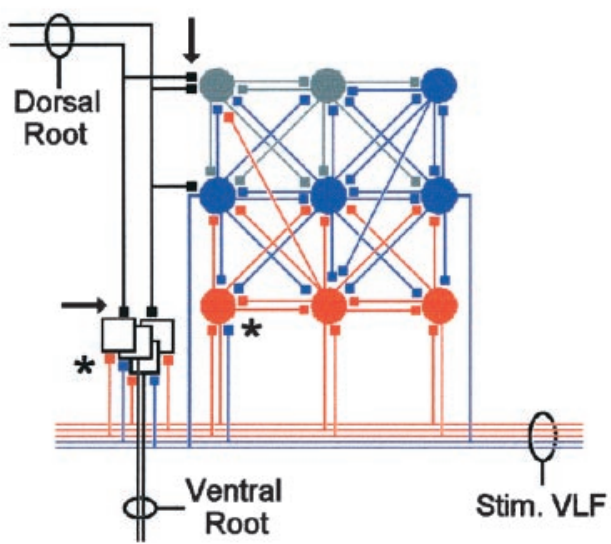

Post-episode

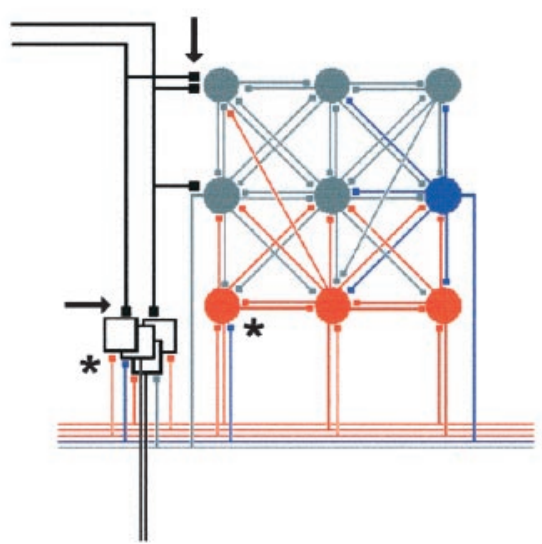

interneuron not activated

by VLF stimulus

VLF-activated interneuron long-latency

VLF-activated interneuron short-latency

motoneuron

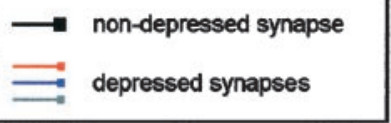

\section{B VLF-evoked ventral root potentials}
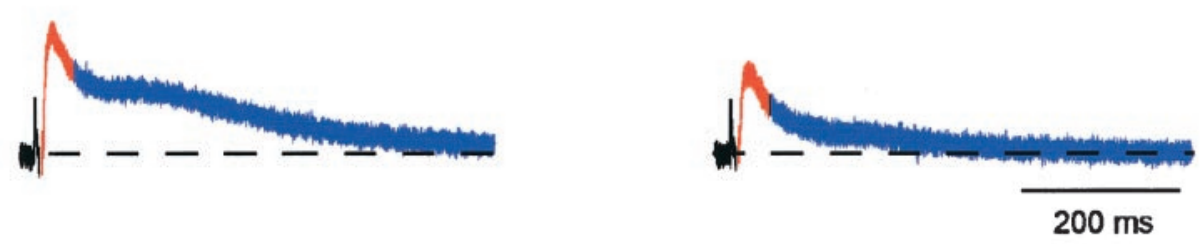

\section{Dorsal-root evoked ventral root potentials}
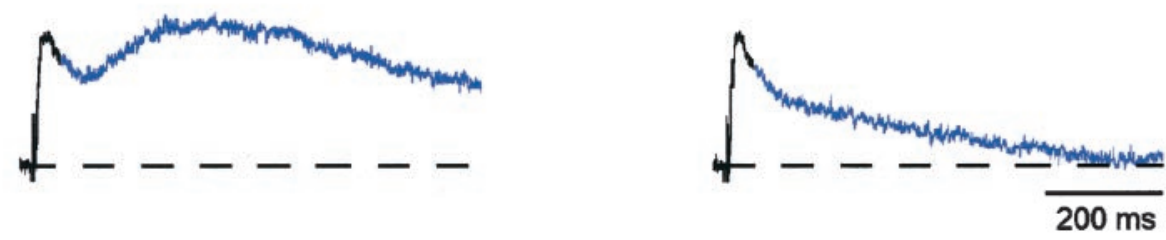

Figure 8. A, Schematic to illustrate the hypothesized circuitry underlying afferent and VLF-evoked responses in motoneurons and their changes after an episode of rhythmic activity. The state of the network before (Pre-episode) and after (Post-episode) an episode is shown in $A$. In each case the diagram illustrates the neurons activated by a single stimulus applied to the VLF (Stim. VLF). Neurons in red are activated directly by the VLF stimulus and contribute to the short-latency $(<50 \mathrm{msec})$ responses evoked in the ventral root. Neurons in blue are activated polysynaptically by the VLF stimulus and contribute to the long-latency ventral root potentials. $B, \mathrm{VLF}$-evoked ventral root potentials, with the short-latency component in red and the long-latency component in blue, corresponding to the pre- and post-episode network configurations shown in $A$. $C$, DR-evoked ventral root potentials, with the short-latency component in black (unmodulated) and the long-latency component in blue. Before an episode we hypothesize that VLF stimulation activates both direct (red) and indirect, polysynaptic (blue) pathways to motoneurons. The polysynaptic pathways are proposed to constitute a network of recurrently connected interneurons that can also be activated by the dorsal roots (dorsal root activation patterns of the network are not illustrated but would be similar to the VLF activation patterns). Before the episode, a suitable stimulus intensity applied to the VLF can activate a significant polysynaptic component. However, after the episode synaptic transmission is depressed at active synapses (asterisks). As a consequence, the short-latency direct responses are depressed, and the number of polysynaptic neurons recruited by the stimulus is reduced, resulting in a decrease in the long-latency component of the response. Notice that the primary afferent dorsal root synapses (arrows) are not depressed after an episode, because they are not firing during the episode. As a result, the short-latency dorsal root evoked responses in the ventral root are not depressed (black component of responses shown in $C$ ). However, the afferent axons also project to the recurrently connected population of interneurons, which are active during the episode. Therefore, the long-latency component of the dorsal root responses (blue) is depressed after the episode.

In addition, the depression could involve some combination of all three effects. We attempted to assess the adequacy of invasion by monitoring the axonal volley recorded in the VLF in response to the VLF stimulus. However, we could not separate the volley from the extracellular field potentials accompanying postsynaptic depolarization. Therefore, a prolonged depression of presynaptic terminal invasion by the test stimulus could contribute to the synaptic depression we have observed.

The second possibility is that the depression occurs at the presynaptic terminal, possibly as a result of a prolonged depression of transmitter release. Such a mechanism has recently been identified as limiting burst duration in disinhibited hippocampal 
slices (Staley et al., 1998), although the time scale for recovery in the hippocampus is much faster (seconds rather than minutes) than in the cord. In addition, transmitter depletion has been implicated in the depression of monosynaptic responses from primary muscle afferents to motoneurons in the neonatal rat spinal cord (Lev-Tov and Pinco, 1992). As a result, prolonged transmitter depletion could be involved in the depression we have observed. However, establishing this definitively will require the difficult task of monitoring transmitter release in the interval between episodes.

The third possibility is that the depression involves a decrease in the postsynaptic currents produced by transmitter release. Consistent with this possibility, we have recently found a postepisode reduction (and recovery) in both the amplitude of miniature synaptic currents (which are TTX-resistant and probably arise from spontaneous transmitter release) and also the postsynaptic currents, produced by iontophoretic application of GABA and glutamate, in voltage-clamped ventral, spinal neurons (Chub and O’Donovan, 1998b; N. Chub and M. J. O’Donovan, unpublished observations). These findings indicate the existence of a post-episode change in the either the conductance or desensitization of postsynaptic receptors and may provide part of the mechanism underlying the post-episode depression of synaptic transmission we have observed.

\section{Depression of long-latency responses}

The amplitude of long-latency polysynaptic responses will depend on the efficacy of synaptic transmission at individual synapses and, second, the extent and time course of interneuronal recruitment triggered by the test stimulus. Our previous work has shown that ventral spinal neurons are subject to a slow depolarization in the interval between episodes (Chub and O'Donovan, 1995). As a consequence, the interneuronal pool will be progressively easier to recruit by the test stimulus as more time passes from the previous episode. These network effects will have the effect of amplifying changes in efficacy at individual synapses and may explain the post-episode depression of long-latency responses evoked by dorsal root or VLF stimulation. Network effects may also account for the potentiation of long-latency responses that occurs on the falling phase of the episode depolarization, because the interneuronal network will be more easily recruited when its constituent neurons are depolarized. By contrast, depolarization will have much less influence on directly activated, monosynaptic responses (for further details, see Fig. 8).

\section{Is postsynaptic activity required for the expression of the depression?}

In several parts of the nervous system, depolarization, firing, or calcium entry can alter the conductance of ligand-gated receptors on the cell membrane and even influence presynaptic transmitter release by a retrograde mechanism (Pitler and Alger, 1992; Soltesz and Mody, 1995; Davis et al., 1998; Mozrzymas and Cherubini, 1998). Our findings suggest that postsynaptic somatic depolarization, calcium entry, and discharge probably do not mediate the depression. For example, prolonged antidromic activation of motoneurons failed to depress VLF-evoked potentials recorded from the same motoneurons. Second, post-episode depression of VLF-evoked synaptic potentials persisted in voltageclamped spinal neurons, including motoneurons. Finally, we found that long-latency, but not short latency, dorsal root evoked potentials in motoneurons were depressed after spontaneous episodes. This observation suggests that events at the level of the motoneuron (which are common to both the short and longlatency responses) are not responsible for the depression.

Collectively, these results suggest that somatic activity is not responsible for the depression. Therefore, we can exclude mechanisms for the regulation of synaptic transmission that depend on postsynaptic somatic depolarization (Pitler and Alger, 1992; Alger and Pitler, 1995). Alternatively, the depression may be mediated, in part, through the activation of second messengers, which are known to modulate the conductance of ligand-gated channels (Roche et al., 1994). This hypothesis can be tested by establishing whether the depression is modified after intracellular injection of agents that alter second messenger function.

It remains possible that dendritic calcium entry and depolarization could mediate the depression we have observed. Such dendritic effects would probably not be influenced by the voltage clamp used in our experiments or by antidromic invasion of motoneurons, unless the spikes invaded the dendrites. Resolving this issue will require the technically difficult task of recording from the dendrites of embryonic spinal neurons.

\section{Role of synaptic depression in the expression of spontaneous episodic activity}

Activity-dependent synaptic depression has been proposed as an important mechanism in the expression of spontaneous activity by recurrently connected, excitatory networks (Streit, 1993; Maeda et al., 1995; Senn et al., 1996; O’Donovan and Chub 1997; O'Donovan et al., 1998a,b; Staley et al., 1998; Tabak et al., 1999). We have now demonstrated that this type of depression is widespread in developing spinal networks. Indeed, it is evident in every active pathway we have examined.

At present, it is not known whether activity-dependent synaptic depression is present in other developing networks that express spontaneous, episodic activity. Some form of refractoriness has been postulated to be involved in wave dynamics in the developing retina, but its mechanism is unknown (Feller et al., 1997). In the embryonic turtle retina, the duration of a spontaneous burst is correlated with the duration of the previous interburst interval (E. Sernagor, personal communication). This correlation is also observed in the activity of embryonic chick spinal networks (Tabak and O'Donovan, 1998), organotypic cultures of the rat spinal cord (Streit, 1993), and the disinhibited adult hippocampus (Staley et al., 1998) and appears to be a marker for the existence of activity-dependent synaptic depression. As such, activitydependent synaptic depression may prove to be a common mechanism underlying the expression of periodic activity by excitatory networks.

\section{REFERENCES}

Alger BE, Pitler TA (1995) Retrograde signaling at $\mathrm{GABA}_{\mathrm{A}}$-receptor synapses in the mammalian CNS. Trends Neurosci 18:333-340.

Blanton MG, Le Turco JJ, Kriegstein AR (1989) Whole cell recording from neurons in slices of reptilian and mammalian cerebral cortex. J Neurosci Methods 30:203-210.

Chub N, O'Donovan MJ (1995) Multi-functional actions of GABA in the regulation of spontaneous activity in the isolated spinal cord of the chick embryo. Soc Neurosci Abstr 21:688.

Chub N, O'Donovan MJ (1998a) Blockade and recovery of spontaneous rhythmic activity following application of neurotransmitter antagonists to spinal networks of the chick embryo. J Neurosci 18:294-306.

Chub N, O'Donovan MJ (1998b) Miniature postsynaptic currents and their modulation by spontaneous activity in the E11-E12 chick embryo spinal cord. Soc Neurosci Abstr 24:1315.

Davis GW, DiAntonio A, Petersen SA, Goodman CS (1998) Postsynaptic PKA controls quantal size and reveals a retrograde signal that regulates presynaptic transmitter release in Drosophila. Neuron 20:305-315. 
Fedirchuk B, O’Donovan MJ (1996) Evoked potentials are transiently depressed following rhythmic activity in the embryonic chick spinal cord. Soc Neurosci Abstr 22:1377.

Feller MB, Butts DA, Aaron HL, Rokhsar DS, Shatz CJ (1997) Dynamic processes shape spatiotemporal properties of retinal waves. Neuron 19:293-306.

Garaschuk O, Hanse E, Konnerth A (1998) Developmental profile and synaptic origin of early network oscillations in the CA1 region of rat neonatal hippocampus. J Physiol (Lond) 507:219-236.

Ho S, O'Donovan MJ (1993) Regionalization and inter-segmental coordination of rhythm generating networks in the spinal cord of the chick embryo. J Neurosci 13:1345-1371.

Itaya SK, Fortin S, Molotchnikoff S (1995) Evolution of spontaneous activity in the rat developing superior colliculus. Can J Pharmacol 73:1372-1377.

Katz LC, Shatz CJ (1996) Synaptic activity and the construction of cortical circuits. Science 274:1133-1138.

Kirkwood A, Lee HK, Bear MF (1995) Co-regulation of long-term potentiation and experience-dependent synaptic plasticity in visual cortex by age and experience. Nature 375:328-331.

Landmesser LT, O'Donovan MJ (1984) Activation patterns of embryonic chick hindlimb muscles recorded in-ovo and in an isolated spinal cord preparation. J Physiol (Lond) 347:189-204.

Lee MT, O’Donovan MJ (1991) Organization of hindlimb muscle afferent projections to lumbosacral motoneurons in the chick embryo. J Neurosci 11:2564-2573.

Lee MT, Koebbe MJ, O'Donovan MJ (1988) The development of sensorimotor synaptic connections in the lumbosacral spinal cord of the chick embryo. J Neurosci 8:2530-2543.

Lev-Tov A, Pinco M (1992) In vitro studies of prolonged synaptic depression in the neonatal rat spinal cord. J Physiol (Lond) 447:149-169.

Lippe WR (1995) Relationship between frequency of spontaneous bursting and tonotopic position in the developing avian auditory system. Brain Res 703:205-213.

Maeda E, Robinson HP, Kawana A (1995) The mechanisms of generation and propagation of synchronized bursting in developing networks of cortical neurons. J Neurosci 15:6834-6845.

McLean HA, Caillard O, Ben-Ari Y, Gaiarsa JL (1996) Bidirectional plasticity expressed by GABAergic synapses in the neonatal rat hippocampus. J Physiol (Lond) 496:471-477.

Mendelson B, Frank E (1991) Specific monosynaptic sensory-motor connections form in the absence of patterned neural activity and motoneuronal cell death. J Neurosci 11:1390-1403.

Mozrzymas JW, Cherubini E (1998) Changes in intracellular calcium concentration affect desensitization of $\mathrm{GABA}_{\mathrm{A}}$ receptors in acutely dissociated P2-P6 rat hippocampal neurons. J Neurophysiol 79:1321-1328.

Nishimaru H, Iizuka M, Ozaki S, Kudo N (1996) Spontaneous motoneuronal activity mediated by glycine and GABA in the spinal cord of rat fetuses in vitro. J Physiol (Lond) 497:131-143.

O'Donovan MJ (1989) Motor activity in the isolated spinal cord of the chick embryo: synaptic drive and firing pattern of single motoneurons. J Neurosci 9:943-958.

O'Donovan MJ, Chub N (1997) Population behavior and selforganization in the genesis of spontaneous rhythmic activity by developing spinal networks. Semin Cell Dev Biol 8:21-28.

O'Donovan MJ, Ritter A (1995) Rhythmic activity patterns of motoneu- rons and interneurons in the embryonic chick spinal cord. In: Neural control of movement (Ferrell WR, Proske U, eds), pp 195-201. New York: Plenum.

O’Donovan MJ, Ho S, Sholomenko G, Yee W (1993) Real-time imaging of neurons retrogradely and anterogradely labeled with calcium sensitive dyes. J Neurosci Methods 46:91-106.

O'Donovan MJ, Ho S, Yee W (1994) Calcium imaging of rhythmic network activity in the developing spinal cord of the chick embryo. J Neurosci 14:6354-6369.

O'Donovan MJ, Chub N, Wenner P (1998a) Mechanisms of spontaneous activity in developing spinal networks. J Neurobiol 37:131-145.

O’Donovan MJ, Wenner P, Chub N, Tabak J, Rinzel J (1998b) Mechanisms of spontaneous activity in the developing spinal cord and their relevance to locomotion. In: Neuronal mechanisms for generating locomotor activity (Kiehn O, Harris-Warrick RM, Jordan LM, Hultborn H, Kudo N, eds), pp 130-141. New York: New York Academy of Sciences.

Pitler TA, Alger BE (1992) Postsynaptic spike firing reduces synaptic $\mathrm{GABA}_{\mathrm{A}}$ responses in hippocampal pyramidal cells. J Neurosci 12:4122-4132.

Roche KW, Tingley WG, Huganir RL (1994) Glutamate receptor phosphorylation and synaptic plasticity. Curr Opin Neurobiol 4:383-388.

Senn W, Wyler K, Streit J, Larkum M, Luscher H-R, Mey H, Muller L, Stainhauser D, Vogt K, Wannier Th (1996) Dynamics of a random neural network with synaptic depression. Neural Networks 9:575-588.

Sernagor E, O'Donovan MJ (1991) Whole-cell patch clamp recordings from rhythmically active motoneurons in the isolated spinal cord of the chick embryo. Neurosci Lett 128:211-216.

Sernagor E, Chub N, Ritter A, O'Donovan MJ (1995) Pharmacological characterization of the rhythmic synaptic drive onto lumbosacral motoneurons in the chick embryo spinal cord. J Neurosci 15:7452-7464.

Soltesz I, Mody I (1995) $\mathrm{Ca}\left({ }^{2+}\right)$-dependent plasticity of miniature inhibitory postsynaptic currents after amputation of dendrites in central neurons. J Neurophysiol 73:1763-1773.

Staley KJ, Longacher M, Bains JS, Yee A (1998) Presynaptic modulation of CA3 network activity. Nat Neurosci 1:201-209.

Streit J (1993) Regular oscillations of synaptic activity in spinal networks in vitro. J Neurophysiol 70:871-878.

Tabak J, O'Donovan MJ (1998) Statistical analysis and intersegmental delays reveal possible roles of network depression in the generation of spontaneous activity in the chick embryo spinal cord. In: Neuronal mechanisms for generating locomotor activity (Kiehn O, HarrisWarrick RM, Jordan LM, Hultborn H, Kudo N, eds), pp 428-431. New York: New York Academy of Sciences.

Tabak J, Senn W, O'Donovan MJ, Rinzel J (1999) Comparison of two models for pattern generation based on synaptic depression. Neurocomputing, in press.

Wenner P, Matise M, Joyner A, O’Donovan MJ (1998) Physiological and molecular characterization of interneurons in the developing spinal cord. In: Neuronal mechanisms for generating locomotor activity (Kiehn O, Harris-Warrick RM, Jordan LM, Hultborn H, Kudo N, eds), pp 425-427. New York: New York Academy of Sciences.

Whelan PJ, O'Donovan MJ (1997) The development of recurrent connections in the embryonic chick. Soc Neurosci Abstr 23:770.2.

Wong RO, Chernjavsky A, Smith SJ, Shatz CJ (1995) Early functional neural networks in the developing retina. Nature 374:716-718. 